\title{
Pengembangan Bahan Ajar Pencak Silat untuk Materi Seni Jurus Tunggal Bagi Ekstrakurikuler
}

\author{
Rodhiya Islamiyah ${ }^{1 *}$ \\ ${ }^{1} J u r u s a n$ Pendidikan Jasmani, Kesehatan dan Rekreasi, Fakultas IImu Keolahragaan, \\ Universitas Negeri Malang, Jalan Semarang No 5, Malang, Jawa Timur, 65145, Indonesia \\ *Penulis koresponden: Rodhiya.islamiyah@gmail.com, 082334007146
}

Artikel diterima: 2 Januari 2020; direvisi: 23 Januari 2021; disetujui: 26 Januari 2021

\begin{abstract}
This study aims to develop teaching materials and make it easier for students to learn single art movements graduallyby promoting the correct technique using audio-visual media which contains learning about the art of single pencak silat art. The results of the research were: 1) the development of teaching material products for extracurricular learners, especially the single art form of audio-visual pencak silat; 2) make it easier for students to understand and memorize the material about the single art of pencak silat correctly.
\end{abstract}

Keyword: development, teaching materials, single art forms, pencak silat

\begin{abstract}
Abstrak: Penelitian ini bertujuan untuk mengembangkan bahan ajar dan mempermudah peserta didik dalam mempelajari gerakan seni jurus tunggal secara bertahap dengan mengedepankan teknik yang benarmenggunakan media audio visual yang berisi tentang pembelajaran seni jurus tunggal pencak silat. Hasil penelitian adalah: 1) pengembangan produk bahan ajar untuk pembelajar eks trakurikuler khususnya seni jurus tunggal pencaksilatyang berbentuk audio visual;2) mempermudah peserta didik dalam memahami dan menghafalkan mate ri tentang seni jurus tunggal pencak silat dengan benar.
\end{abstract}

Kata kunci: pengembangan, bahan ajar, seni jurus tunggal, pencak silat

\section{PENDAHULUAN}

Olahraga adalah salah satu bentuk kegiatan jasmani yang di dalamnya terdapat aktivitas fisik yang terencana atau terstruktur yang melibatkan gerak tubuh berulang-ulang dengan tujuan untuk meningkatkan kebugaran jasmani yang di dalamnya terdapat permainan, perlombaan, dan kegiatan jasmani. Setiap orang dapat memilih dan melakukan olahraga sesuai dengan kebutuhan masing-masing karena setiap jenis olahraga memiliki fungsi yang relatif berbeda meskipun memiliki tujuan yang sama. Saat ini olahraga yang banyak digemari mulai dari anak-anak hingga dewasa adalah olahraga jenis bela diri. Bela diri banyak disukai selain karena tujuan utamanya untuk olahraga, juga memiliki tujuan dapat mempertahankan diri. Sehingga banyak sekali dari kalangan masyarakat memilih untuk mempelajari jenis olahraga bela diri. Salah satu olahraga jenis bela diri yang diminati adalah pencak silat. Pencak silat merupakan bagian dari warisan budaya asli bangsa Indonesia. Tidak sedikit dari penduduk Indonesia yang mempelajari bela diri pencak silat. Pencak silat menjadi olahraga yang diminati karena pencak silat sudah dipertandingkan di kancah Internasional. Selain itu, pencak 
silat juga memiliki empat aspek utama, yakni aspek mental spiritual, aspek seni budaya, aspek bela diri, dan aspek olahraga.

Pencak silat telah merambah masuk ke dalam dunia pendidikan Indonesia, mulai dari tingkat dasar, menengah, hingga perguruan tinggi. Pencak silat telah menjadi bagian dari ekstrakurikuler yang memiliki banyak peminat. Salah satunya di SDN Klojen Kota Malang. Olahraga pencak silat menjadi salah satu ekstrakurikuler di SDN Klojen Kota Malang yang cukup diminati oleh peserta didik dengan berbagai prestasi yang telah diraih. Dalam latihan ekstrakurikuler pencak silat materi seni jurus tunggal terdapat beberapa teknik dasar yang dapat dipelajari peserta didik, seperti memukul, menendang, elakan, tangkisan, kuda-kuda, dengan menggunakan senjata ataupun tidak.

Ekstrakurikuler merupakan pendidikan nonformal yang dilakukan di luar jam pelajaran yang bertujuan untuk membantu perkembangan peserta didik sesuai dengan kebutuhan, potensi, bakat dan minat yang dilaksanakan di setiap sekolah. Pada kenyataannya ekstrakurikuler sangat penting dalam pendidikan karena peserta didik di tuntut untuk aktif dalam kegiatan tersebut dan mendapatkan pengalaman langsung. Akan tetapi pendidik di SDN Klojen Kota Malang dalam mengajarkan materi seni jurus tunggal masih menggunakan metode ceramah, demonstrasi, dan juga praktik yang dapat menimbulkan rasa bosan sehingga motivasi dan minat belajar peserta didik akan turun. Sistem pengajaran ini banyak disebut sebagai sistem pengajaran bersifat konvensional dalam pendidikan, yaitu proses pembelajaran yang masih berpusat pada pendidik, di mana pendidik aktif menjelaskan sedangkan peserta didik bersifat pasif. Jika hal ini berlangsung terus menerus maka minat, motivasi, aktivitas, dan hasil belajar peserta didik juga akan menurun.

Di era teknologi seperti saat ini mampu memberikan banyak manfaat untuk dunia pendidikan seperti media pembelajaran (Kumar \& Nanda, 2018). Pendidik seharusnya bisa memanfaatkan dan mengaplikasikan hasil teknologi yang ada dalam suatu pembelajaran (Kumar Basak, Wotto, \& Bélanger, 2018). Salah satunya melalui pengembangan media audio visual. Media audio visual seperti DVD dapat merangsang semangat dan motivasi belajar peserta didik karena ada unsur suara dan gambar dengan warna-warni yang dapat menarik perhatian peserta didik untuk belajar (Al-Rahmi \& Zeki, 2017; Chassiakos et al., 2016; Hakim, 2018; Mao, 2014). Pembelajaran dengan menggunakan media audio visual diharapkan agar peserta didik bisa berlatih untuk lebih mudah mengingat, membayangkan, dengan penghayatan terhadap apa yang pernah dilihat, didengar, dan dirasakan untuk dimunculkan kembali ke dalam aktivitas terutama saat latihan di lapangan sesuai dengan kejadian yang ditampilkan melalui media audio visual. Media video merupakan sarana atau alat yang tepat untuk pembelajaran keterampilan seni pencak silat. Karena pada video unsur-unsur seperti suara, gambar, garis simbol dan gerak akan ditampilkan (Adi \& Fathoni, 2019, 2020a, 2020b; Fathoni, 2018). Media audio visual dapat memudahkan pemahaman dan memperkuat ingatan, sehingga pada akhirnya diharapkan peserta didik dapat mengoptimalkan kemampuan dan potensinya, terutama pada materi seni jurus tunggal pencak silat.

Pembelajaran seni jurus tunggal sangat penting diterapkan pada anak usia dini, karena ingatan yang ada pada anak usia dini sangat kuat dan gerakan motoriknya masih sempurna. Sebagai gambaran untuk mempelajari dan menguasai dengan baik seni jurus tunggal pencak silat ini memerlukan waktu yang relatif lama dan sangat diperlukan ketekunan, kesabaran dan pemahaman gerak secara rinci dari jurus-jurus tersebut. Proses pembelajaran keterampilan seni jurus tunggal pencak silat yang di dalamnya mencakup pembelajaran teori dan praktik akan lebih menarik bila menggunakan berbagai media, baik itu media audio visual maupun media lain yang dapat membantu membelajarkan gerak seni jurus tunggal. Media audio visual dalam pembelajaran teori seni jurus tunggal dapat memotivasi peserta didik untuk belajar, dengan menggunakan media ini pendidik dapat menyampaikan teori sekaligus menunjukkan langsung gambaran teori yang dimaksudkan sebelum melaksanakan langsung pembelajaran praktik di lapangan.

\section{METODE}

Penelitian ini dilaksanakan di SDN Klojen Kota Malang pada tahun ajaran 2019/2020. Penelitian dan pengembangan ini menggunakan model konseptual yang mengacu pada model pengembangan (Van Hoecke, 2016). Dalam prosedur pengembangan ada langkah-langkah sebagai berikut: (1) Melakukan Need Assessment atau analisis kebutuhan (2) Melakukan Front-end analysis atau analisis awal dan akhir (3) Melakukan Design atau desain produk. (4) Development atau pengembangan produk (5) Implementation atau pelaksanaan, (6) Evaluation atau evaluasi. 
Jenis data yang digunakan dalam pengembangan ini adalah data kualitatif dan kuantitatif. Data kualitatif diperoleh dari hasil tinjauan ahli yaitu, ahli media pembelajaran, ahli pencak silat, dan ahli pembelajaran ekstrakurikuler. Sedangkan data kuantitatif diperoleh dari analisis kebutuhan untuk mengetahui persentase kebutuhan produk yang akan dikembangkan serta dari data uji coba kelompok kecil dan uji coba kelompok besar.

Instrumen pengumpulan data terdiri dari tiga instrumen yakni Instrumen berupa angket. Angket digunakan untuk mengumpulkan data kuantitatif analisis kebutuhan dan penilaian peserta didik kelas 3-5 SDN Klojen Kota Malang terhadap pengembangan media audio visual sebagai pembelajaran jurus seni tunggal pencak silat yang akan dibuat sebagai produk awal dan akhir. Wawancara digunakan untuk mendapatkan informasi/masalah yang terjadi di dalam penelitian. Pada penelitian ini, observasi digunakan untuk mengumpulkan data mengenai keadaan lapangan. Rumus mengolah data berupa deskriptif persentase adalah sebagai berikut (Kafle, 2013; Leguina, 2015) :

$$
\text { audience }=\frac{T S e}{T S h} \times 100 \%
$$

\section{Keterangan:}

TSe $=$ Total skor empirik.

TSh $=$ Total skor maksimal.

Tabel 1 Penggolongan Persentase Hasil Pengolahan Data

\begin{tabular}{|c|c|c|}
\hline No. & Kriteria Pencapaian nilai (Keefektifan) & Tingkat efektifan/validitas \\
\hline 1 & $81 \%-100 \%$ & $\begin{array}{l}\text { Sangat valid, sangat efektif, sangat } \\
\text { tuntas, dapat digunakan tanpa } \\
\text { perbaikan. }\end{array}$ \\
\hline 2 & $61 \%-80 \%$ & $\begin{array}{l}\text { Cukup valid. cukup efektif, cukup } \\
\text { tuntas, dapat digunakan namun } \\
\text { perlu perbaikan kecil. }\end{array}$ \\
\hline 3 & $41 \%-60 \%$ & $\begin{array}{l}\text { Kurang valid, kurang efektif, } \\
\text { kurang tuntas, perlu perbaikan } \\
\text { besar, disarankan tidak } \\
\text { dipergunakan. }\end{array}$ \\
\hline 4 & $21 \%-40 \%$ & $\begin{array}{l}\text { Tidak valid, tidak efektif, tidak } \\
\text { tuntas, tidak dapat digunakan. }\end{array}$ \\
\hline 5 & $0 \%-20 \%$ & $\begin{array}{l}\text { Sangat tidak valid, sangat tidak } \\
\text { efektif, sangat tidak tuntas, tidak } \\
\text { bisa digunakan. }\end{array}$ \\
\hline
\end{tabular}

HASIL

Produk yang dihasilkan pada penelitian pengembangan ini merupakan sesuatu produk bahan ajar untuk pembelajar ekstrakurikuler khususnya seni jurus tunggal pencak silat yang berbentuk audio visual, yang berisi materi gerak seni jurus tunggal pencak silat. Pada penelitian pengembangan ini data diperoleh dengan menggunakan kuesioner analisis kebutuhan untuk peserta didik dan pendidik atau pelatih ekstrakurikuler pencak silat di SDN Klojen Kota Malang. Data hasil terdiri dari data hasil tinjauan para ahli (ahli media, ahli pencak silat, ahli pembelajaran), uji coba kelompok kecil, uji coba lapangan (kelompok besar).

Rancangan produk yang dibuat oleh peneliti pengembangan, dievaluasi oleh ahli media pembelajaran yaitu oleh Bapak Eko Pramono Adi, S.I.P, M.Si yang merupakan Dosen Jurusan Teknologi Pendidikan, Fakultas IImu Pendidikan, Universitas Negeri Malang, yang berpengalaman dalam penelitian dan pengembangan media instruksional. Dari rekapitulasi ahli media pembelajaran menyatakan keseluruhan tampilan dalam produk pengembangan bahan ajar yang berupa media audio visual seni jurus tunggal pencak silat 92,05\% 
sangat menarik dan dapat digunakan sebagai media alternatif pembelajaran gerak seni jurus tunggal pencak silat. Adapun data kualitatif yang diperoleh yaitu berupa saran dan masukan. Adapun saran dan masukan dari ahli media pembelajaran yaitu, secara umum keseluruhan sudah bagus, kejelasan gerakan, dan penjelasan sudah berbentuk tulisan dan diiringi dengan suara penjelasan yang sudah sangat jelas.

Rancangan produk pengembangan bahan ajar seni jurus tunggal pencak silat yang telah dibuat, dievaluasi oleh ahli pencak silat yaitu bapak Eko Wahyudi S.Pd yang merupakan Wasit Juri Daerah Jawa Timur Kelas 2. Hasil rekapitulasi ahli pencak silat menyatakan hasil 85,86\% menarik dan pengembangan diharapkan dapat diterapkan dalam pembelajaran ekstrakurikuler pencak silat di setiap Sekolah Dasar. Adapun data kualitatif yang diperoleh yaitu berupa saran dan masukan, adapun saran dan masukan dari ahli pencak silat menyatakan bahwa keseluruhan rancangan produk pengembangan bahan ajar seni jurus tunggal dapat digunakan sebagai alternatif pembelajaran seni jurus tunggal pencak silat.

Rancangan produk pengembangan bahan ajar seni jurus tunggal yang telah dibuat, dievaluasi oleh ahli pembelajaran yaitu lbu Nanik Agustina M.Pd yang merupakan guru dan juga pelatih di SDN Klojen Kota Malang. Ahli pembelajaran merasa bahwa rancangan produk pengembangan bahan ajar seni jurus tunggal pencak silat sangat bagus. Hasil rekapitulasi dari ahli pembelajaran menyatakan keseluruhan tampilan dalam pengembangan bahan ajar seni jurus tunggal pencak silat yang berupa media audio visual $93,75 \%$ sangat menarik dan dapat digunakan sebagai media alternatif pembelajaran seni jurus tunggal pencak silat dan perlu digandakan agar dapat mempermudah peserta didik untuk mempelajarinya di rumah.

Hasil uji coba kelompok kecil tentang pengembangan bahan ajar seni jurus tunggal pencak silat melalui media audio visual diperoleh dari hasil pengisian angket yang disebarkan pada 10 peserta didik yang mengikuti ekstrakurikuler pencak silat di SDN Klojen Kota Malang yang menggunakan (random sampling) karena pemilihannya dilakukan secara acak tanpa memperhatikan tingkatan uji coba kelompok kecil menunjukkan hasil $88,05 \%$ masuk dalam kategori sangat valid sehingga dapat disimpulkan bahwa pengembangan bahan ajar seni jurus tunggal bagi ekstrakurikuler pencak silat dapat digunakan sebagai alternatif untuk latihan yang dapat menarik peserta didik untuk belajar seni jurus tunggal pencak silat, mempermudah, dan lebih cepat menghafal seni jurus tunggal pencak silat.

Uji coba lapangan (kelompok besar) dengan menggunakan angket kuesioner yang diberikan kepada 30 peserta didik yang mengikuti ekstrakurikuler pencak silat di SDN Klojen Kota Malang yang menggunakan (random sampling) karena pemilihannya dilakukan secara acak tanpa memperhatikan tingkatan Data hasil uji coba kelompok kecil terhadap produk pengembangan bahan ajar seni jurus tunggal bagi ekstrakurikuler pencak silat di SDN Klojen Kota Malang dengan bentuk media audio visual. Hasil uji coba lapangan (kelompok besar) diperoleh hasil 92,02\% yang termasuk dalam kategori sangat valid sehingga dapat dinyatakan layak untuk digunakan sebagai alternatif untuk pembelajaran seni jurus tunggal pencak silat di SDN Klojen Kota Malang.

\section{PEMBAHASAN}

SDN Klojen Kota Malang merupakan salah satu Sekolah Dasar Negeri di Malang. Sekolah tersebut terletak di pusat Kota Malang. Berdasarkan observasi awal yang dilakukan penulis di sekolah tersebut dengan penyebaran angket analisis kebutuhan (need assessment) melalui kuesioner terhadap satu pendidik ekstrakurikuler di SDN Klojen Kota Malang diperoleh temuan sebagai berikut : 1.) Fasilitas ekstrakurikuler SDN Klojen Kota Malang terbilang sudah terpenuhi. 2.) Sekolah ini memiliki lapangan yang menjadi satu untuk fasilitas olahraga yang dapat dipakai untuk pembelajaran ekstrakurikuler di sekolah tersebut. 3.) Pendidik mengajarkan ekstrakurikuler pencak silat dari kelas $3-6$, tetapi kelas 6 hanya untuk semester gasal. 4.) Pendidik memberikan materi seni jurus tunggal pencak silat. 5.) Pendidik memberikan model ceramah dan demonstrasi terlebih dahulu, kemudian mempraktikkan. 6.) Sekolah ini juga dilengkapi fasilitas pembelajaran berbasis teknologi seperti, LCD (Liquid Crystal Display). 7.) Pendidik ekstrakurikuler pencak silat SDN Klojen Kota Malang menyatakan perlu model bahan ajar media audio visual pembelajaran yang lebih mudah dilaksanakan, dimengerti oleh peserta didik, mudah dipahami oleh peserta didik, menyenangkan, dan menarik minat peserta didik untuk mempelajari seni jurus tunggal IPSI.

Data yang diperoleh dari hasil uji validitas para ahli yaitu: satu ahli media, satu ahli pencak silat, satu ahli pembelajaran sudah memenuhi kriteria sangat valid dan layak untuk di gunakan sebagai bahan ajar seni jurus 
tunggal pencak silat di SDN Klojen Kota Malang. Pengembangan media pembelajaran ekstrakurikuler seni jurus tunggal yang berisi materi gerak seni jurus tunggal pencak silat. Untuk memaksimalkan produk pembelajaran seni jurus tunggal pencak silat dengan bentuk media audio visual, produk yang sudah ada harus direvisi terlebih dahulu dengan berpedoman pada saran dan masukan yang telah di berikan oleh para ahli.

Hasil uji coba kelompok kecil dan uji coba lapangan dengan data diperoleh menggunakan kuesioner analisis kebutuhan untuk peserta didik yang sudah memenuhi kriteria kelayakan produk yang sudah ditentukan. Uji coba yang dilakukan kepada peserta didik dilakukan kepada siswa yang mengikuti ekstrakurikuler pencak silat di SDN Klojen Kota Malang dengan hasil yang di dapat dalam uji coba kelompok kecil dengan 10 peserta didik dan uji coba lapangan 30 peserta didik sangat valid dan memudahkan peserta didik memahami seni jurus tunggal pencak silat.

Media audio-visual merujuk pada penggunaan komponen suara (audio) dan komponen gambar (visual), pembuatan audio visual membutuhkan beberapa peralatan (Dwiyogo, 2018; Purwaningtyas \& Hariyadi, 2017) Menurut Akbar \& Hariyanto (2020) bahan ajar merupakan salah satu alat atau sarana untuk melakukan pembelajaran yang berisi tentang materi, metode, batasan-batasan, dan cara mengevaluasi pembelajaran yang didesain secara sistematis dan mekanik dalam rangka mencapai tujuan pembelajaran. Kegiatan ekstrakurikuler adalah kegiatan yang dilakukan di luar jam pelajaran biasa pada waktu libur sekolah yang dilakukan baik di sekolah maupun di luar sekolah, dengan tujuan untuk memperluas pengetahuan siswa, mengenal hubungan antara berbagai mata pelajaran, menyalurkan bakat dan minat. Sedangkan menurut Mirfa'ani \& Nurrochmah (2020) pencak silat adalah gerak bela diri yang berasal dari kebudayaan Melayu, yang dapat digunakan untuk bela diri, melatih kebugaran tubuh (olahraga), pertunjukan dan pendidikan etika. Jurus tunggal adalah peragaan jurus yang gerakannya sudah diatur atau dibakukan sebelumnya terdiri atas jurus tangan kosong dan senjata (Ramadhan, Ahmad, \& Mansoor, 2017; Saputro \& Siswantoyo, 2018). IPSI sebagai organisasi yang menaungi seluruh kegiatan pencak silat dan menciptakan suatu seni gerakan atau rangkaian jurus-jurus yang terdiri dari gerak langkah, pukulan, tendangan, tangkisan, elakan, baik memakai senjata maupun tidak yang tersusun sebagai jurus tunggal (Fatma Chomsiatun, 2017; Punkastyo, 2018).

Dapat disimpulkan dari hasil uji coba produk pengembangan bahan ajar seni jurus tunggal pencak silat yang telah dilaksanakan, produk pengembangan yang berbentuk media audio visual diharapkan agar peserta didik bisa berlatih untuk lebih mudah mengingat, membayangkan, dengan penghayatan terhadap apa yang pernah dilihat, didengar, dan dirasakan untuk dimunculkan kembali ke dalam aktivitas terutama saat latihan di lapangan sesuai dengan kejadian yang ditampilkan melalui media audio visual sehingga keterampilan seni juru tunggal pencak silat peserta ekstrakurikuler di SDN Klojen Kota Malang.

\section{KESIMPULAN}

Hasil skor rekapitulasi ahli media 92,05\% sangat menarik dan dapat digunakan sebagai media alternatif pembelajaran gerak seni jurus tunggal pencak silat. Hasil rekapitulasi ahli pencak silat menyatakan hasil $85,86 \%$ menarik dan pengembangan diharapkan dapat diterapkan dalam pembelajaran ekstrakurikuler pencak silat di setiap Sekolah Dasar. Hasil rekapitulasi dari ahli pembelajaran menyatakan keseluruhan tampilan dalam pengembangan bahan ajar seni jurus tunggal pencak silat yang berupa media audio visual $93,75 \%$ sangat menarik. Hasil uji coba yang dilaksanakan uji coba kelompok kecil dan uji coba kelompok besar (lapangan), hasil uji coba kelompok kecil $88,05 \%$ masuk dalam kategori sangat valid sehingga dapat disimpulkan bahwa pengembangan bahan ajar seni jurus tunggal bagi ekstrakurikuler pencak silat dapat digunakan sebagai alternatif untuk latihan yang dapat menarik peserta didik untuk belajar seni jurus tunggal pencak silat, hasil uji coba lapang 92,02\% yang termasuk dalam kategori sangat valid sehingga dapat dinyatakan layak untuk digunakan sebagai alternatif untuk pembelajaran seni jurus tunggal pencak silat di SDN Klojen Kota Malang.

Media pengembangan bahan ajar seni jurus tunggal dengan bentuk media audio visual yang dikemas dalam bentuk DVD dengan mempertimbangkan tingkat kemudahan dalam penggunaannya. Kondisi ini diharapkan bisa membantu memecahkan salah satu masalah yang terkait dengan penggunaan media audio visual bagi ekstrakurikuler pencak silat di SDN Klojen Kota Malang. 


\section{DAFTAR PUSTAKA}

Adi, S., \& Fathoni, A. F. (2019). Development of Learning Model Based on Blended Learning in Sports School. https://doi.org/10.2991/acpes-19.2019.2

Adi, S., \& Fathoni, A. F. (2020a). Blended Learning Analysis for Sports Schools in Indonesia. International Journal of Interactive Mobile Technologies (IJIM), 14(12), 149-164. Retrieved from https://www.onlinejournals.org/index.php/i-jim/index

Adi, S., \& Fathoni, A. F. (2020b). The effectiveness and efficiency of blended learning at sport schools in Indonesia. International Journal of Innovation, Creativity and Change.

Akbar, R. A., \& Hariyanto, E. (2020). Pengembangan Bahan Ajar Pencak silat Untuk Siswa Sekolah Dasar. Sport Science and Health, 2(7), 350-356. Retrieved from http://journal2.um.ac.id/index.php/jfik/index

Al-Rahmi, W. M., \& Zeki, A. M. (2017). A model of using social media for collaborative learning to enhance learners' performance on learning. Journal of King Saud University - Computer and Information Sciences. https://doi.org/10.1016/j.jksuci.2016.09.002

Chassiakos, Y. R., Radesky, J., Christakis, D., Moreno, M. A., Cross, C., Hill, D., ... Swanson, W. S. (2016). Children and adolescents and digital media. Pediatrics. https://doi.org/10.1542/peds.2016-2593

Dwiyogo, W. (2018). Developing a Blended Learning-Based Method for Problem-Solving in Capability Learning. Tojet - The Turkish Online Journal of Educational Technology.

Fathoni, A. F. (2018). The Role of Blended Learning on Cognitive Step in Education of Sport Teaching by Adjusting the Learning Style of the Students. https://doi.org/10.2991/isphe-18.2018.49

Fatma Chomsiatun. (2017). Nilai-Nilai Pendidikan Karakter Dalam Ekstrakurikuler Pencak Silat Di MI Islamiyah Gebangsari Kecamatan Tambak Kabupaten Banyumas - Repository IAIN Purwokerto.

Hakim, L. (2018). PENGEMBANGAN MEDIA PEMBELAJARAN PAI BERBASIS AUGMENTED REALITY. Lentera Pendidikan : Jurnal IImu Tarbiyah Dan Keguruan. https://doi.org/10.24252/lp.2018v21n1i6

Kafle, N. P. (2013). Hermeneutic phenomenological research method simplified. Bodhi: An Interdisciplinary Journal. https://doi.org/10.3126/bodhi. v5i1.8053

Kumar Basak, S., Wotto, M., \& Bélanger, P. (2018). E-learning, M-learning and D-learning: Conceptual definition and comparative analysis. E-Learning and Digital Media. https://doi.org/10.1177/2042753018785180

Kumar, V., \& Nanda, P. (2018). Social Media in Higher Education. International Journal of Information and Communication Technology Education. https://doi.org/10.4018/ijicte.2019010107

Leguina, A. (2015). A primer on partial least squares structural equation modeling (PLS-SEM). International Journal of Research \& Method in Education. https://doi.org/10.1080/1743727x.2015.1005806

Mao, J. (2014). Social media for learning: A mixed methods study on high school students' technology affordances and perspectives. Computers in Human Behavior. https://doi.org/10.1016/j.chb.2014.01.002

Mirfa'ani, N., \& Nurrochmah, S. (2020). Survei Kemampuan Kondisi Fisik Peserta Kegiatan Ekstrakurikuler Pencak Silat Perisai Diri di Sekolah Menengah Atas. Sport Scien, 2(4), 239-246. Retrieved from http://journal2.um.ac.id/index.php/jik/article/view/11752/5577

Punkastyo, D. A. (2018). Perancangan Aplikasi Tutorial Jurus Dasar Beladiri Cimande Menggunakan Metode Prototype. Jurnal Informatika Universitas Pamulang. https://doi.org/10.32493/informatika. ßi2. 1433

Purwaningtyas, W. D. D., \& Hariyadi, I. (2017). Pengembangan Modul Elektronik Berbasis Online Dengan Program Edmodo. Jurnal Pendidikan. https://doi.org/http://dx.doi.org/10.17977/jp. V2i1.8471

Ramadhan, R., Ahmad, H. A., \& Mansoor, A. Z. (2017). Translasi Pencak Silat Kedalam Film Animasi (Studi Kasus Film Kung Fu Panda). Journal of Visual Art and Design. https://doi.org/10.5614/j.vad.2017.9.2. 4

Saputro, D. P., \& Siswantoyo, S. (2018). Penyusunan norma tes fisik pencak silat remaja kategori tanding. Jurnal Keolahragaan. https://doi.org/10.21831/jk.v6i1.17724 
Van Hoecke, M. (2016). Methodology of Comparative Legal Research. Law and Method. https://doi.org/10.5553/rem/.000010 